\title{
Determination and modelling of the cure shrinkage of epoxy vinylester resin and associated composites by considering thermal gradients
}

\author{
Yasir Nawab $^{\mathrm{a}, \mathrm{b}, *}$, Xavier Tardif $^{\mathrm{a}}$, Nicolas Boyard ${ }^{\mathrm{a}, 1}$, Vincent Sobotka ${ }^{\mathrm{a}}$, Pascal Casari ${ }^{\mathrm{b}}$, \\ Frédéric Jacquemin $^{\mathrm{b}}$ \\ a Université de Nantes, CNRS, Laboratoire de Thermocinétique de Nantes, UMR 6607, La Chantrerie, rue Christian Pauc, BP 50609, 44306 Nantes cedex 3, France \\ ${ }^{\mathrm{b}}$ Université de Nantes, Institut de Recherche en Génie Civil et Mécanique, UMR CNRS 6183, 37 boulevard de l'Université, BP 406, 44600 Saint-Nazaire, France
}

Quantification and understanding of the evolution of chemical shrinkage of thermoset polymers is of crucial importance for modelling of residual strains and stresses. Thermal properties of resin and the strong coupling between chemical reactions and thermal fields lead to non-negligible thermal and curing degree gradients in the part. In this paper, modelling of the volume chemical shrinkages of an unsaturated epoxy vinylester resin and associated glass fibre composites is proposed, by taking into account the coupling between volume variation and thermal gradients. Modelling is also compared with the measurements done with a home-made instrument (PVT- $\alpha$ ). Results suggest that chemical shrinkage is non linear as a function of degree of cure. Moreover, for an equal mass of resin, chemical shrinkage of resin carrying fibres is lesser than the neat resin.

\section{Keywords:}

A. Polymer-matrix composites (PMCs) D. Differential scanning calorimetry (DSC) Cure shrinkage

\section{Introduction}

During the curing cycle, thermoset composites undergo the residual strains and stresses. These latter depend mostly on the shrinkage behaviour of the polymer matrix, from the point where curing stresses cannot be relaxed anymore. The matrix shrinkage may have a thermal and/or chemical origin. The chemical shrinkage is a direct consequence of crosslinking of the thermosetting polymer and its characterisation is thus of crucial interest for modelling the residual stresses $[1,2]$ and shape evolution of composite part during curing [3].

Several studies have been carried out to determine the curing based dimensional changes in thermoset resins using the various dilatometric techniques. These techniques include capillary-type dilatometer [4,5], plunger type dilatometer [6-8], gravimetric method [9,10], rheometer [11], pycnometer [11,12], fibre Bragg grating [13-17], thermomechanical analyser [18], dynamic mechanical analyser [19,20], ultrasonic waves [21], using optical fibres, etc.

Since chemical shrinkage is expressed as a function of degree of cure, another instrument (DSC in most cases) was used to

\footnotetext{
* Corresponding author at: Université de Nantes, CNRS, Laboratoire de Thermocinétique de Nantes, UMR 6607, La Chantrerie, rue Christian Pauc, BP 50609, 44306 Nantes cedex 3, France.

E-mail addresses: yasir.nawab@univ-nantes.fr (Y. Nawab), nicolas.boyard@ univ-nantes.fr (N. Boyard)

1 Tel.: +33 240 683115; fax: +33240683141
}

determine degree of cure. This tends to be prejudicial against a wholly accurate interpretation, since the experimental conditions may not exactly be the same. Furthermore, all the above mentioned instruments (except plunger type) work in low pressure, which does not match the industrial conditions.

Keeping in view the limitations of these instruments, a plunger type device called PVT- $\alpha$ mould was developed in our lab, which works in industrial like conditions (i.e., adjustable pressure up to $10 \mathrm{MPa}$ in moulding cavity and temperature up to $200^{\circ} \mathrm{C}$ ), and is able to measure simultaneously the flux density hence the degree of cure, volume and temperature of mould surface for a given pressure. This instrument has already been used to determine the chemical shrinkage of thermoset resins [22-25].

In most of above mentioned studies, the chemical shrinkage was found by neglecting the thermal gradients, and evolution of shrinkage curve versus degree of cure was found linear. But in reality, thermal gradients exist in the thermoset resins due to the strong coupling between heat transfers and reaction kinetics, and due to low thermal diffusivity of resin. These gradients become more significant in case of thick parts and may change considerably the evolution of shrinkage curve. Therefore, there is a real need to quantify these gradients, and then determine the chemical shrinkage by considering them.

Studies on determination of volume chemical shrinkage of composites are found rare. For example, Russell [26] used GNOMIX PVT device for determination of global volume chemical shrinkage of UD laminated (carbon/epoxy) composite. Problems faced were the toxicity of sample confining fluid (mercury), voids in the 
sample and inaccurate determination of degree of cure. Same device was also used to study the epoxy moulding compound with and without fillers [27]. Holst et al. [28] determined the volume chemical shrinkage of epoxy system containing fillers using a laser scanning dilatometer. Some authors also carried out some significant studies to find the in-plane chemical shrinkage of composites, such as Daniel et al. [29] which followed the warpage of 16 plies unidirectional glass/epoxy laminated plate. In a comprehensive study, Olivier [30] proposed a setup to determine the chemical shrinkage and thermo-mechanical mechanical properties of laminated composite samples.

In the present article, volume chemical shrinkage of vinylester resin was determined under high pressure and heating ramp conditions by considering the thermal gradients. Moreover, volume chemical shrinkage of glass/vinylester laminated composite was determined (under pressure, and heating ramp conditions) to study the effect of reinforcement on the chemical shrinkage while considering the thermal gradients. Some results on thermokinetic characterisation of the resin are also presented.

The volume measurements of resin and composite during curing were taken using PVT- $\alpha$ mould. The contributions of thermal expansion and chemical shrinkage to the experimental displacement curve during the curing cycle were then deduced from thermal and curing fields. These fields were computed by solving heat transfer and volume variation equation coupled to crosslinking kinetics, and by assuming a shrinkage model. The evolution of the cure shrinkage was then compared to experimental curves for which temperature gradients were neglected. The calculated shrinkage at the end of reaction is found very close to the experimental values.

\section{Materials and methods}

Vinylester resin (DERAKANE MOMENTUM 411-350 epoxy vinyl ester) was used with $0.05 \mathrm{wt} \%$ of initiator (Cobalt Naphthenate) and $1 \mathrm{wt} \%$ of Catalyst (NOROX MEKP-925H Methylethylketone peroxide (MEKP)). These proportions were selected to get maximum gel time at room temperature $\left(30 \pm 10 \mathrm{~min}\right.$ at $\left.25^{\circ} \mathrm{C}\right)$. Crossply glass/vinylester composite having two fibre volume fractions
( $32 \mathrm{vol} \%$ and $49 \mathrm{vol} \%$ ) were selected to study the effect of the fibres on chemical shrinkage. Following thermal cycle was used for the curing of samples in PVT $-\alpha$ mould at the pressure of $0.65 \mathrm{MPa}$.

1. Equilibrating the system at room temperature and maintaining for $2 \mathrm{~min}$.

2. Heating to $180{ }^{\circ} \mathrm{C}$ at the rate of $4{ }^{\circ} \mathrm{C} / \mathrm{min}$, and maintaining at $180^{\circ} \mathrm{C}$ for $10 \mathrm{~min}$.

3. Cooling to room temperature at $4{ }^{\circ} \mathrm{C} / \mathrm{min}$.

Studied samples have diameter equal to $40.5 \pm 1 \mathrm{~mm}$ and thickness about $6 \mathrm{~mm}$.

\subsection{Description of PVT- $\alpha$ mould}

PVT- $\alpha$ mould (Fig. 1) consists of a piston which is able to move in a cylindrical stainless steel cavity having a $61 \mathrm{~mm}$ internal diameter. The mould is designed so that heat transfers are 1D through the sample thickness. The heating is ensured by three heaters located at the top and bottom to heat the piston and cavity respectively. The mould is placed between two platens of an electric press. The position of the piston is adjusted in real time to keep the pressure constant. More details about this device are given in $[31,32]$. In this instrument, the experiments can be done on bulk samples.

Before starting PVT- $\alpha$ experiment, resin and the associated composites were sealed in a low modulus elastomer capsule, which is selected to avoid the jamming of the mould. Infusion of resin in capsule was done using vacuum assistance to remove air bubbles. Capsule was then placed in PVT- $\alpha$ cavity under the piston, which moves following the variations of the sample volume to get a constant pressure. These variations were recorded by LVDT-type displacement sensor with a precision of $1 \mu \mathrm{m}$ and a limit of $10 \mathrm{~mm}$. The heat flux was measured by two heat flux sensors [33] placed in the bottom of cavity and in the piston. Since the composite sample was placed in the deformable but incompressible elastomer cavity, the pressure is assumed to be hydrostatic and the surface of the elastomer, on which the pressure was applied, does not vary. As a consequence, the measured thickness is directly related to the sample volume and its variations.

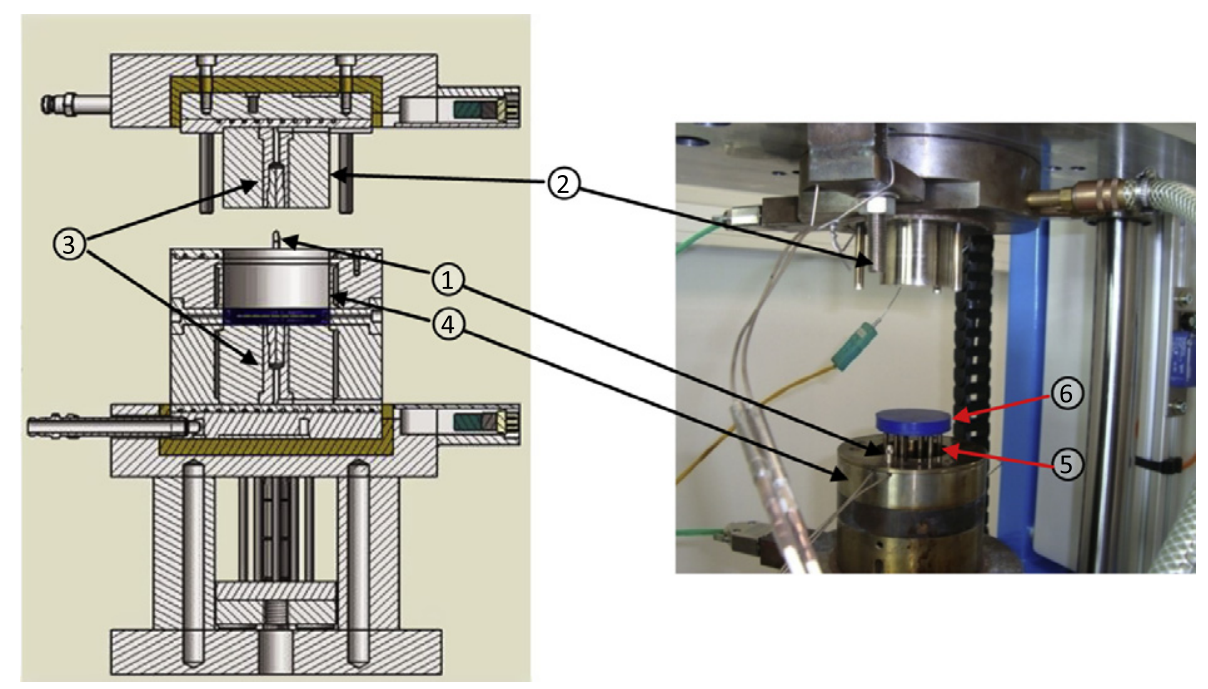

(1)Displacement sensor (2) Piston (3) Heat flux sensors (4) Mould cavity (5)Ejectors

(6) Capsule containing sample

Fig. 1. General view of PVT- $\alpha$ device. 


\section{Thermo-physical characterisation of the resin}

\subsection{Determination and modelling of glass transition temperature}

Glass transition temperature ' $\mathrm{Tg}$ ' has a strong effect on thermophysical properties and kinetics of reaction during isothermal curing or when the sample temperature reaches close to $\mathrm{Tg}$ during curing. Therefore, it is important to determine and to model it versus the cure degree $(\alpha)$. The glass transition temperature of raw re$\sin (\operatorname{Tg} 0)$ and of fully cured resin $(\operatorname{Tg} \infty$ were found equal to $-55.5^{\circ} \mathrm{C}$ and $118.9^{\circ} \mathrm{C}$ respectively by using DSC. The classical model developed by Pascault and Williams [34] was used to describe the unique relationship (1) between $T g$ and $\alpha$.

$\frac{(\operatorname{Tg}-\operatorname{Tg} 0)}{(\operatorname{Tg} \infty-\operatorname{Tg} 0)}=\frac{\alpha \cdot k}{[1-(1-k) \cdot \alpha]}$

where ' $k$ ' is a structure-dependent parameter and was found equal to 0.332 to fit the experimental data.

\subsection{Characterisation of thermal conductivity}

In the present study, guarded hot plate method [35] was used to measure thermal conductivity $(\lambda)$ of cured resin between $25^{\circ} \mathrm{C}$ and $75^{\circ} \mathrm{C}$. A second technique based on an optimisation approach, was also applied to determine the thermal conductivity of resin in both raw and cured resin states [36]. It consists in identifying thermal conductivity from temperature measurements done at several locations through the sample thickness. The sample was placed between two heating plates, assuming that heat transfers are 1D. Temperatures recorded closest to the plates were used as boundary conditions, whereas the others were used for estimation. Identification was done by minimising a least square criterion using the conjugate gradient algorithm. The gradient of the criterion was determined by solving a set of adjoint equations. Thermal conductivity versus temperature results were fitted using linear regressions (2)-(4). The effect of the rubbery state $(T>T g)$ on thermal conductivity can be noted.

$$
\begin{aligned}
& \lambda=0.165\left(\mathrm{~W} \mathrm{~m}^{-1} \mathrm{~K}^{-1}\right) \quad\left(\mathrm{W} / \mathrm{m} \mathrm{K}, \text { raw resin, } 20^{\circ} \mathrm{C}<T<70^{\circ} \mathrm{C}\right) \\
& \lambda=1.41 \times 10^{-4} T+0.187 \quad\left(\mathrm{~W} / \mathrm{m} \mathrm{K}, \text { cured resin, with } T \text { in }{ }^{\circ} \mathrm{C}, T<\operatorname{Tg} \infty\right) \\
& \lambda=-1.63 \times 10^{-4} T+0.216 \quad\left(\mathrm{~W} / \mathrm{m} \mathrm{K}, \text { cured resin, with } T \text { in }{ }^{\circ} \mathrm{C}, T>\operatorname{Tg} \infty\right)
\end{aligned}
$$

\subsection{Determination of heat of cure and specific heat}

DSC (TA Q200 from TA Instruments ${ }^{\circledR}$ ) was used to measure these characteristic parameters of the resin. Classical dynamic scans (heating rate: $5^{\circ} \mathrm{C} / \mathrm{min}$, across a temperature range from -10 to $170{ }^{\circ} \mathrm{C}$ ) were performed under nitrogen purge. Sample weights ranged between 7 and $9 \mathrm{mg}$.

The total heat of cure was determined by integration of the exothermal peak area using a sigmoid integration line, resulting into average value (five experiments) of $324.9 \pm 3.6 \mathrm{~J} / \mathrm{g}$. During the curing cycle, the resin passes from the raw (uncured liquid) to the cured rubbery and ultimately, to the cured glassy state (during cooling). $C p$ in each of these three states was determined from DSC experiments using a sapphire calibration (5), according to the DIN standard 51007.

$C p=\frac{d H / d t}{m(d T / d t)} E$

Here ' $E$ ' is the calibration coefficient, whose values were determined from experiment on synthetic sapphire disc with known $C p$. The variations of $C p$ with temperature $\left(T\right.$ in $\left.{ }^{\circ} \mathrm{C}\right)$ for all resin states were found linear and fitted accordingly

$$
\begin{aligned}
& C p_{\text {raw }}=0.00073 T+1.8544 \quad\left(\mathrm{~J} \mathrm{~g}^{-1} \mathrm{~K}^{-1} \text {, with } T \text { in }{ }^{\circ} \mathrm{C}\right) \\
& C p_{\text {cured,glassy }}=0.0049 T+1.1805 \quad\left(\mathrm{Jg}^{-1} \mathrm{~K}^{-1} \text {, with } T \text { in }{ }^{\circ} \mathrm{C}\right), \text { if } T \leqslant \operatorname{Tg} \infty \\
& C p_{\text {cured,rubbery }}=0.0017 T+1.8292 \quad\left(\mathrm{Jg}^{-1} \mathrm{~K}^{-1} \text {, with } T \text { in }{ }^{\circ} \mathrm{C}\right) \text {, if } T>\operatorname{Tg} \infty
\end{aligned}
$$

The $C p$ of solid cured resin during the glass transition was modeled from the values of $C p$ in cured glassy state and that in cured rubbery state using:

$$
\begin{aligned}
C p_{\text {cured }}(T)= & C p_{\text {glassy }}(1-I) \\
& +(I) C p_{\text {rubbery }}, \text { during glass transition with } I \\
= & \frac{1}{2}\left(1+\tan h\left(\frac{2 d}{\delta}\right)\right)
\end{aligned}
$$

where $d$ is the half temperature range of glass transition $\left(17.5^{\circ} \mathrm{C}\right.$ in our case), and $\delta$ is a temperature factor to determine (found equal to $17{ }^{\circ} \mathrm{C}$ in our case).

Knowing the values of $\rho$ and $C p$ in raw and cured states, a mixing law [37] (10) was used to get $(\rho C p)$ during the curing for any temperature and degree of cure.

$(\rho C p)_{\text {resin }}(T, \alpha)=\alpha \cdot(\rho C p)_{\text {cured, rubbery }}(T)+(1-\alpha) \cdot(\rho C p)_{\text {raw }}(T)$

\subsection{Characterisation of kinetics of reaction}

Within the aim to compute the cure degree field through the sample during the curing process, the knowledge of reaction kinetics is of crucial importance due to its strong coupling with heat transfers. The determination of this field will be required later onto model the evolution of shrinkage.

A model of cure reaction should be able to describe the kinetics of reaction in material as well as the physical phenomenon like vitrification. A number of models have been reported for thermoset resins, which can be categorised as phenomenological and mechanistic. Phenomenological models can accurately describe the main features of the kinetic reaction ignoring the elementary reactions between the different species. They are mainly used at the expense of mechanistic ones for simplicity reasons. Among these models, one can cite the catalytic models [38,39]. Prime [40] proposed a such simple model, relating the kinetics of crosslinking with the degree of cure. Kamal and Sourour [41] proposed the first comprehensive model, used later on in several studies. Adolf [42,43] considered the effect of glass transition in his model. Bailleul [44] proposed a model stating the kinetic rate as a product of temperature function and degree of cure function. This model was also be extended to include the effects of diffusion associated to network formation and thus $\mathrm{Tg}[1]$.

In our case, the resin cure is modelled by an empirical autocatalytic kinetic equation that describes polymerisation rate through a combination of Arrhenius and polynomial functions proposed by Bailleul [44]. It is also assumed that the Arrhenius relationship and the diffusion rate act in parallel, leading to

$\frac{d \alpha}{d t}=W(v(T)) \cdot K(T) \cdot G(\alpha) \cdot F_{\text {diffusion }}(\alpha)$

$W(v(T))$ is a function corresponding to the induction of reaction. Note that it can also be used to consider an inhibition period when inhibitors are added to the resin. It is defined as $W(v(T))=0$ if $v(T) \geqslant 0, W(v(T))=1$ if $v(T)<0$, where $v(T)$ is expressed as follows:

$v(T)=t_{\text {ref }}-\int_{0}^{t_{\text {ind }}} \exp \left[-B \cdot\left(\frac{T_{\text {ref }}}{T}-1\right)\right] d t$

$K(T)$ is an Arrhenius function that describes the dependence of rate of reaction on temperature 


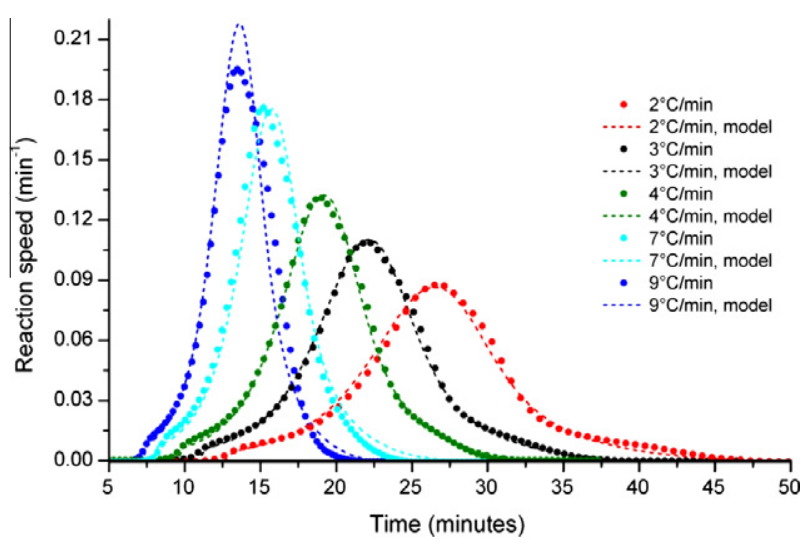

Fig. 2. Experimental (DSC) and modelled reaction rates for several heating rates.

Table 1

Parameters of kinetic model.

\begin{tabular}{ll}
\hline$W(v(t))$ & $B=25.363, T_{\text {ref }}=373 \mathrm{~K}, t_{\text {ref }}=0.5 \mathrm{~min}$ \\
\hline$K(T)$ & $K_{\text {ref }}=176.2737 \mathrm{~min}^{-1}, A=12.9238, T_{\text {ref }}=373 \mathrm{~K}$ \\
$G(\alpha)$ & $G_{0}=5.4232 \times 10^{-4}, G_{1}=9.0522 \times 10^{-3}, G_{2}=-2.3720 \times 10^{-2}$, \\
& $G_{3}=2.6544 \times 10^{-2}, G_{4}=-1.9107 \times 10^{-2}, G_{5}=6.6887 \times 10^{-3}$ \\
$F_{\text {diffusion }}$ & $\alpha_{C}=0.99, E_{1}=8.75$
\end{tabular}

$K(T)=K_{\text {ref }} \exp \left[-A\left(\frac{T_{\text {ref }}}{T}-1\right)\right]$

$G(\alpha)$ is a polynomial function (14) that determines the dependence of reaction rate on the degree of cure.

$G(\alpha)=\sum_{i=0}^{6} G_{i} \alpha^{i}$

Finally, the diffusion-controlled effects are included in the model using the semi-empirical relationship (15) proposed by Chern and Poehlein [45].

$F_{\text {diffusion }}(\alpha)=\frac{1}{1+\exp \left(E_{1}\left(\alpha-\alpha_{c}\right)\right)}$

$F_{\text {diffusion }}$ is the function used to describe the diffusion control in cure reaction associated to the decrease in mobility of molecules due to network formation. The diffusion control is sensitive to the absolute value $|T-T g(\alpha)|$ [34]. In Eq. (15), it is considered that diffusion becomes the controlling factor when $\alpha$ approaches $\alpha_{c}$. Here $\alpha_{c}$ and $E_{1}$ are parameters to be determined.

Fig. 2 shows the reaction rates versus time graph of experimental and model curves, plotted for five heating rates. The model parameters (Table 1 ) were determined by using CureKinetics ${ }^{\circledR}$ software. This model has been validated by comparing the temperature recorded by a $80 \mu \mathrm{m}$-diameter thermocouple (K-type) located in the middle of a resin sample and the calculated one using (17a)-(17d). Calculated and recorded temperatures were found in a satisfactory agreement.

\section{Determination of the resin cure shrinkage by using PVT- $\alpha$ and modelling}

\subsection{Interpretation of $P V T-\alpha$ curves}

Vinylester resin used in the study is a low-temperature polymerisation resin so care was taken to start PVT $-\alpha$ experiment quickly after the resin preparation, but still it took 4-6 min. In order to take into account the possible heat losses of the mould, thermal expansions of the LVDT sensor, the elastomer and the mould, an aluminium disc with known properties was placed in the elastomer capsule to be submitted to the same thermal cycle as the sample. This data was then used as "reference" experiment. After data treatment, the total heat flux density $(\varphi)$ and the thickness variation purely associated to resin were obtained.

In Fig. 3, a typical evolution of the resin thickness (representative of volume) during the curing cycle, sample surface temperature and the associated degree of cure $\alpha$ (calculated from heat flux density data) are plotted versus time. During the heating cycle, this thickness variation is the result of thermal expansion and chemical shrinkage, while the only prominent phenomenon during cooling cycle was the thermal contraction.

Linear (A-B) part of the thickness curve represents the thermal expansion of neat resin. As the reaction starts at the low temperature, this region is very small and it is difficult to determine CTE (coefficient of thermal expansion) of raw resin accurately. Between the points $B$ and $C$ (crosslinking zone), the chemical shrinkage of resin also appeared in addition to thermal expansion, and tended to decrease the sample thickness up to the point $C$ where the resin was close to be fully cured (as $\alpha=1$ ). A linear thickness curve from point $C$ to $D$ shows that the only prominent effect was again the thermal expansion.

When the thickness is plotted versus temperature, slopes of part $A B$ and $C D$ of that curve gives the CTE of raw and cured rubbery resin respectively.

In order to get the value of thermal expansion coefficient CTE at each time step in the crosslinking zone (B-C), a mixing law [23] (16) was used.

$$
\begin{aligned}
\mathrm{CTE}(\alpha)= & \mathrm{CTE}_{\text {raw }} \cdot(1-\alpha)+\alpha \\
& \cdot \mathrm{CTE}_{\text {rubbery } \quad\left(\mathrm{K}^{-1}, \text { during crosslinking phase }\right)}
\end{aligned}
$$

In the beginning, when the reaction was not started, an endothermal effect was observed on the heat flux curve (Not shown for brevity) due to the heating of the sample. However as the temperature increased, the reaction started resulting in exothermal peak. At about $118{ }^{\circ} \mathrm{C}$, the resin seemed to be fully cured (or reaction became too slow to observe any effect on the heat flux curve). In the isothermal step, flux curve returned to zero level showing that there was no more thermal or chemical phenomenon. Total heat of cure $(327 \pm 4.1 \mathrm{~J} / \mathrm{g})$ was determined by integrating the heat flux curve using sigmoid base line, which is found in agreement with DSC results $(324.9 \pm 3.6 \mathrm{~J} / \mathrm{g})$.

\subsection{Effect of thermal gradients on macroscopic shrinkage during the crosslinking}

To deduce the exact contribution of thermal expansion and chemical shrinkage to the experimental displacement curve, the temperature and cure degree fields (which depend on the sample thickness variation and coupled to reaction kinetics) have to be computed simultaneously during the curing cycle. Within this context, we described heat transfer and volume variation (17a) coupled to crosslinking kinetics (11). The used domain is cylindrical. Heat transfer is through the thickness, and the sample is assumed to be isothermal along the radius at a given thickness. Since $\rho, C p, \lambda$ depend on the temperature and cure degree, the problem to be solved is non-linear. Initial temperature field (17d) is known, and boundary conditions are of the third kind (17b)-(17c). The problem is given by the following set of equations, where $h$ is the inverse of the thermal resistance induced by the silicon capsule and thermal contact, and $T_{\text {mould1 }}, T_{\text {mould2 }}$ are the surface temperatures of the mould cavity and piston respectively. 


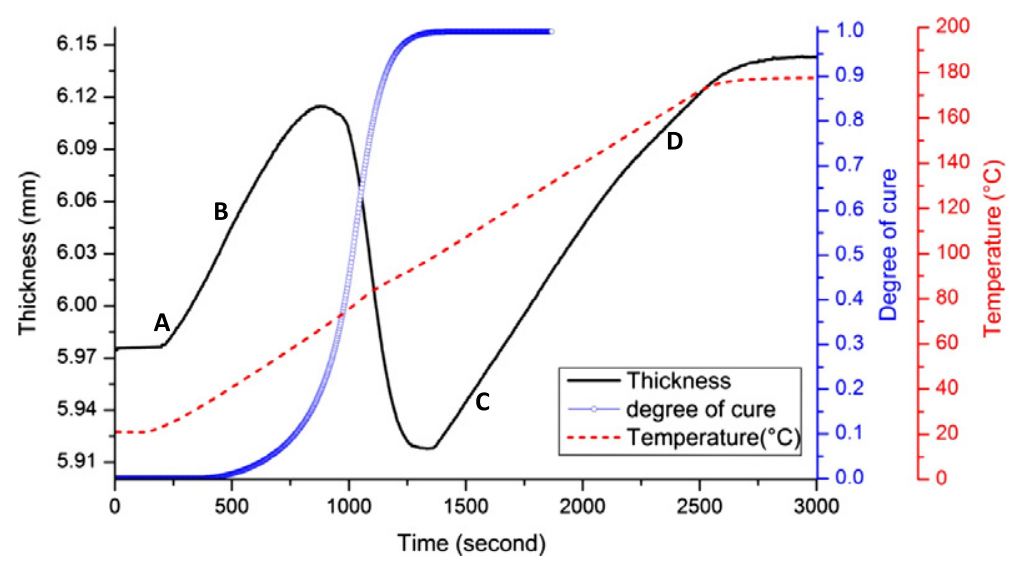

Fig. 3. Thickness, temperature and degree of cure of neat resin sample versus time.

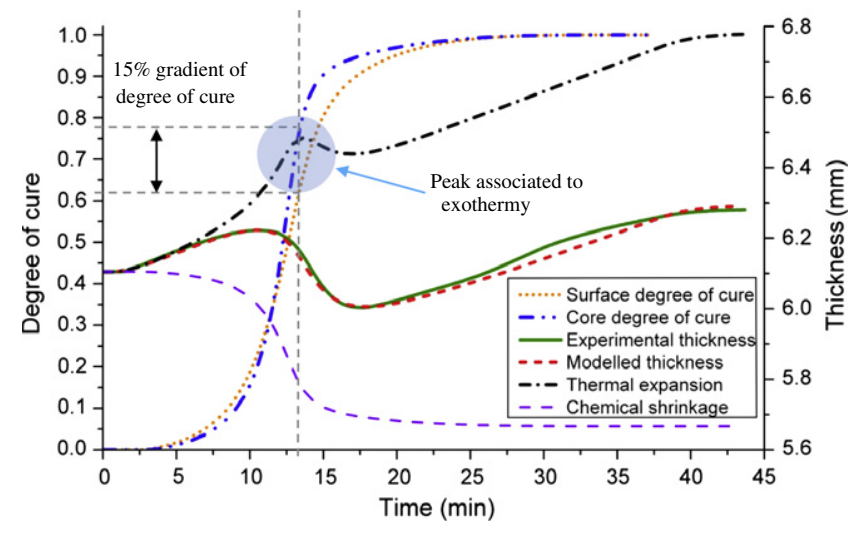

Fig. 4. Calculated thermal expansion and shrinkage contributions to the global displacement curve recorded for neat resin sample considering temperature gradients.

$$
\begin{aligned}
\rho C p(T, \alpha) \frac{\partial T}{\partial t} & =\frac{\partial}{\partial t}\left(\lambda(T, \alpha) \frac{\partial T}{\partial x}\right)+\rho(T, \alpha) \cdot \Delta H \cdot \frac{\partial \alpha(T)}{\partial t}, x \\
& \in] 0, L[, \forall t>0
\end{aligned}
$$

$-\left.\lambda \frac{\partial T}{\partial x}\right|_{x=0}=h\left(T_{\text {mould } 1}-T\right), \quad x=0, \quad \forall t>0$

$-\left.\lambda \frac{\partial T}{\partial x}\right|_{x=L}=h\left(T-T_{\text {mould2 }}\right), \quad x=L, \quad \forall t>0$

$T(0, x)=T_{\text {ini }}(x)$

In order to calculate the temperature at each step of thickness, Crank-Nicholson method was used to discretize 1 - D heat conduction equation. The sample was supposed to compose of a number of slices (meshes). The volume of the mesh (an element of discretization) changes due to chemical shrinkage and thermal expansion. Therefore, the problem is a moving boundary one with constant mesh mass. Since temperature is varying through the thickness, all the meshes may not necessarily have the same volume. The volume variation of an elementary volume mesh $\mathrm{d} V_{i}$ can be expressed by:

$$
\frac{1}{d \rho_{i}(T, \alpha)}=d V_{i}(T, \alpha)=d V_{0 i}(1+\operatorname{CTE}(\alpha) \cdot \Delta T+\operatorname{CCS} \cdot \Delta \alpha)
$$

With $\mathrm{d} V_{0 i}$ initial volume, and $\Delta T$ and $\Delta \alpha$ the temperature and degree of cure variations between two time steps. Since the resin was in the liquid/gel state during curing and a hydrostatic pressure was applied over the surface, all the changes in volume appear along the thickness, and radius was assumed to be constant.
Assuming that the cure shrinkage is a linear function of ' $\alpha$ ' (observed when shrinkage was calculated by neglecting thermal gradients and plotted versus degree of cure, as shown in Fig. 7) in each mesh of the neat resin and composite samples, we thus define a coefficient of chemical shrinkage (CCS) to describe this linear relationship. Both coefficients (CCS and CTE) were then used to model the total thickness variation of each mesh such that the difference between modelled and experimental thickness was minimum. By iterative calculation, thickness of each mesh was calculated according to its temperature and degree of cure, and then summed to get final thickness at each time step.

In Fig. 4, experimental displacement curve and the modelled one for the neat resin are plotted. Thermal expansion curve represents the thickness of sample including the thermal expansion. Chemical shrinkage curve corresponds to the thickness evolution induced by resin crosslinking.

According to our calculations, the temperature difference between the surface and the core of the sample during curing reached up to $20^{\circ} \mathrm{C}$ (for $6 \mathrm{~mm}$ thick sample), which is significant. This difference will become higher for the thicker sample. The peak observed on the "thermal expansion" curve corresponds to exothermy of reaction and shows that present study is closer to reality as compared to literature, since it has not been presented before. The thermal gradient induces the gradient of the degree of cure as well, which will ultimately induce the gradients of cure dependent properties. Therefore, surface and core degree of cure versus time are also plotted on the same graph. The difference between the surface and the core degree of cure reached up to $15 \%$ of total degree of cure $\Delta \alpha=0.15$, as this parameter is strongly coupled to

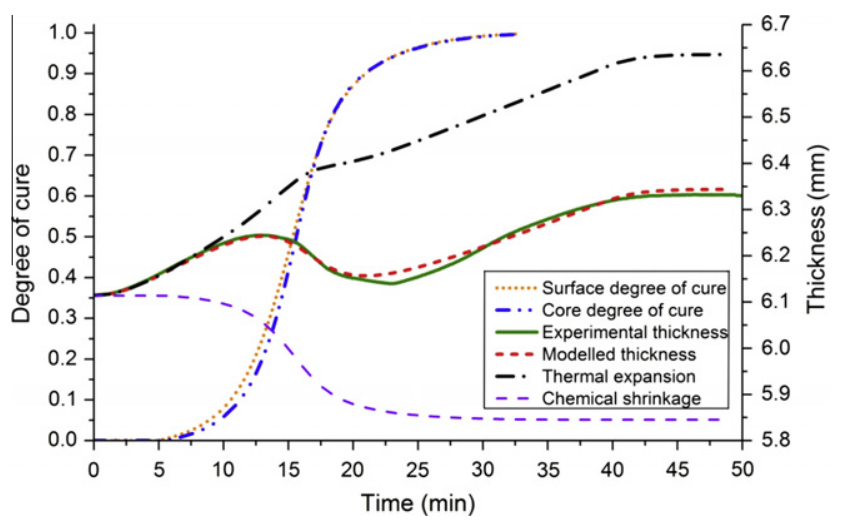

Fig. 5. Calculated thermal expansion and shrinkage contributions to the global displacement curve of composite (32 vol\% fibres). 
the temperature field. Therefore, evolution of shrinkage versus degree of cure will be different at difference points in the thickness. The final value of computed volume shrinkage for resin was found equal to $-7.14 \mathrm{vol} \%$, which is in agreement with literature shrinkage value [25] found by neglecting the gradients.

The composite experiments were also treated in the same way, and the results are presented in Figs. 5 and 6 for 32 vol\% and 49 vol\% fibre volume fraction respectively. The volume shrinkage induced by the crosslinking was found equal to $-4.40 \%$ for the composite with $32 \mathrm{vol} \%$ of fibres, and $-2.76 \%$ for that containing $49 \mathrm{vol} \%$ of fibres. The lower volume fraction of resin leads to the lower temperature and degree of cure gradients in composite samples, as expected. The proposed shrinkage model, coupled to thermal effects can thus be used to simulate dilatometric behaviour of both resin and associated composites.

Classically, the shrinkage is plotted versus degree of cure $[23,25,28]$. Therefore, it was also interesting for us to analyse the evolution of the volume shrinkage versus the degree of cure. It is previously demonstrated that the degrees of cure as a function of time are different through the sample thickness (Fig. 4-6). Therefore, we plotted the chemical shrinkage (for each sample) versus the mean cure degree (solid curves), surface cure degree (big dotted curves), and cure degree in the core of the part (small dotted curves) as shown in Fig. 7.

Regarding resin, a significant difference between the evolution of shrinkage curves plotted versus surface and core degree of cure can be observed. The difference of magnitude of shrinkage between these curves reaches $1 \%$ ( $14 \%$ of total chemical shrinkage) at $\alpha=0.65$, which is significant. For comparison with literature results $[23,25]$, a curve for resin, calculated by neglecting the thermal gradients, is also plotted in Fig. 7 (dashed curve). This curve evolves in the similar way to the shrinkage curve versus core degree of cure (calculated considering the gradients). The results show that the shrinkage curve versus degree of cure is not linear when thermal gradients are taken in account (for any of three cases). Moreover, it can be noted that dotted curves act as upper and lower bounds of the solid line curve. As thermal gradients become lower in the presence of fibres (amount of resin decreases), these bounds become narrower for composites. This behaviour continues with increasing the fibre volume fraction.

Taking into account thermal gradients through the thickness of the composite sample, we can observe that the volume shrinkage of composites can be simply modelled assuming a linear behaviour of the volume variation of the matrix shrinkage in each element of the discretization scheme. Compared to the resin sample, the curves associated to composites have a more linear evolution which can be attributed to the fact that the temperature gradients

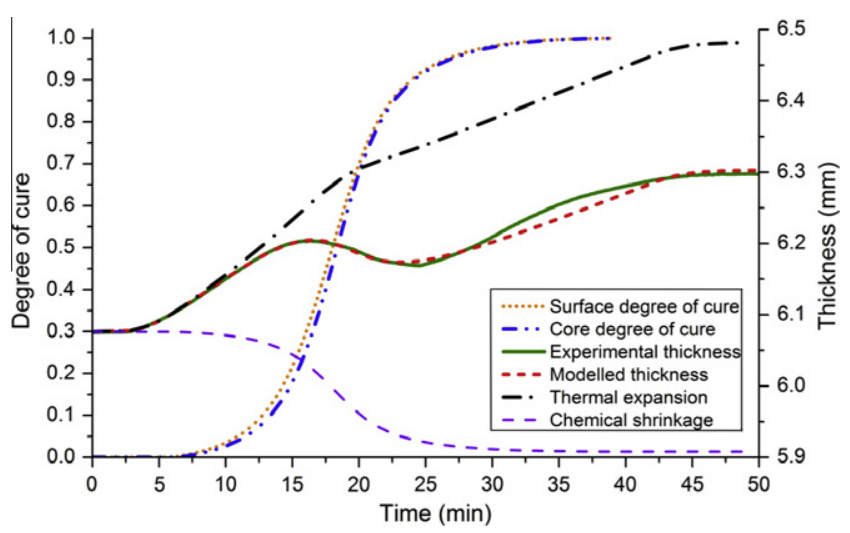

Fig. 6. Calculated thermal expansion and shrinkage contributions to the global displacement curve of composite (49 vol\% fibres).

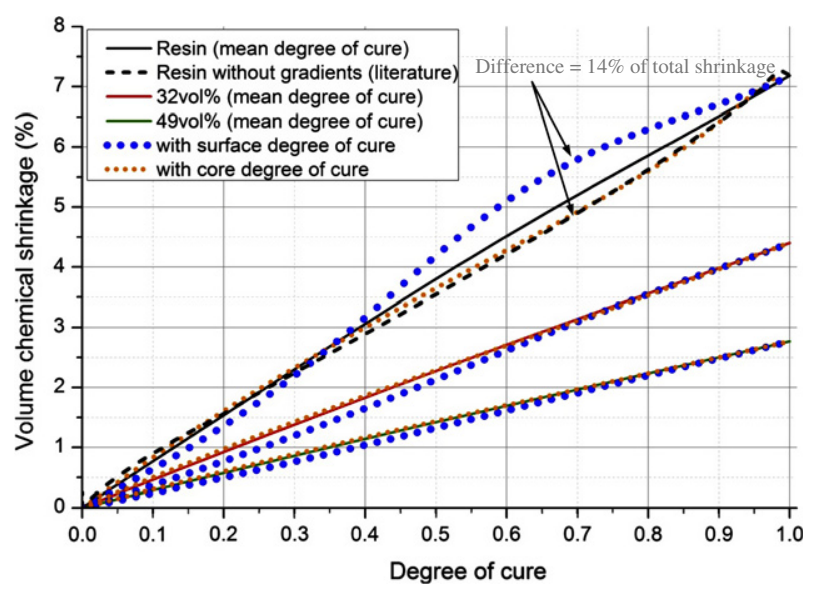

Fig. 7. Variation of volume chemical shrinkage versus degree of cure for three samples, with different fibre volume fractions.

are rather low when the volume fibre fraction increases. Even if anisotropic shrinkage exists, it is neither highlighted from the experimental nor from the modelled volume variations.

To study the effect of presence of fibres on the chemical shrinkage, shrinkage of each composite sample (found experimentally) was converted to shrinkage of an equivalent neat resin sample. This equivalent shrinkage of composite with $32 \%$ and 49 vol\% fibres were found equal to $-6.55 \%$ and $-5.51 \%$ respectively. It can be noted that for the same mass of resin, shrinkage of resin without fibres is higher than the shrinkage of resin with the fibres. It means that presence of fibres hindered the resin to shrink chemically during curing. The effect becomes prominent by increasing the fibre fraction.

Using the chemical shrinkage of resin and fibre fraction, volume chemical shrinkage of composite can be found by using:

$\left(\right.$ Shrinkage $\left._{\text {composite }}\right)=\left(\right.$ Shrinkage $\left._{\text {resin }}\right)-($ fibre vol\% $) \times H$

where $H$ is a hindrance factor, which can be found experimentally. Its value depends on type of reinforcement and resin. In the present study, its value was found equal to 0.03 .

\section{Conclusion}

In this study, mould PVT- $\alpha$ was used to determine the volume chemical shrinkage of vinylester resin and glass/vinylester composites [0/90] with two fibre volume fractions, during the curing by taking into account the thermal gradients. Firstly, the thermophysical properties and the kinetics of the resin were determined and validated. Thermal and cure degree gradients were then computed to calculate the exact thermal expansion and chemical shrinkage contributions (which are coupled) to the sample volume variation during the curing cycle (heating step). It was done by assuming a linear model to describe the shrinkage evolution and by solving a heat conduction equation coupled to crosslinking kinetics model and a moving boundary problem. The large amount of heat of reaction, which was released in a short time range, led to a thermal expansion peak and temperature and cure degree gradients through the sample thickness for neat resin. The final resin chemical shrinkage value was found to be equal to $-7.1 \mathrm{vol} \%$. These observations were attenuated for composites, since the volume fraction of resin was lower. Moreover, the graph of the calculated shrinkage versus the mean cure degree showed that curves are not fully linear. This seems consistent when the thermal and cure degree gradients exist in the sample. 
Finally, it was found that for an equal mass, chemical shrinkage of resin carrying fibres is lesser than the shrinkage of neat resin. This result can lead to the assumption that a part of the shrinkage has been hindered by the fibres which will reside as residual stresses in the composite part.

\section{References}

[1] Abou Msallem Y, Jacquemin F, Boyard N, Poitou A, Delaunay D, Chatel S. Material characterization and residual stresses simulation during the manufacturing process of epoxy matrix composites. Compos Part A: Appl Sci Manuf 2010;41(1):108-15.

[2] Shimbo M, Yamabe M, Miyano Y. Viscoelastic analysis of residual stress in thermosetting resins introduced during curing process. In: Allison IM, editor. 11th International conference on, experimental mechanics, Oxford-UK; 1998. p. $1325-1330$.

[3] Nawab Y, Jacquemin F, Casari P, Boyard N, Sobotka V. Evolution of chemical and thermal curvatures in thermoset laminated composite plates during the fabrication process. J Compos Mater 2012. http://dx.doi.org/10.1177/ $\underline{0021998312440130}$

[4] Snow AW, Armistead JP. A simple dilatometer for thermoset cure shrinkage and thermal expansion measurements. J Appl Polym Sci 1994;52(3):401-11.

[5] Yan-Jyi H, Chiou-Ming L. Volume shrinkage characteristics in the cure of lowshrink unsaturated polyester resins. Polymer 1996;37:401-12.

[6] Mark K, Lee LJ. Development of a dilatometer and its application to low-shrink unsaturated polyester resins. J Appl Polym Sci 1992;45(1):37-50.

[7] Mark K, Shailesh M, Lee LJ. Dilatometric study of low profile unsaturated polyester resins. Polym Eng Sci 1995;35(10):823-36.

[8] Madhukar MS, Genidy MS, Russell JD. A new method to reduce cure-induced stresses in thermoset polymer composites, Part I: Test method. J Compos Mater 2000;34(22):1882-904.

[9] Li C, Potter K, Wisnom MR, Stringer G. In-situ measurement of chemical shrinkage of MY750 epoxy resin by a novel gravimetric method. Compos Sci Technol 2004;64(1):55-64.

[10] Parlevliet PP, Bersee HEN, Beukers A. Shrinkage determination of a reactive polymer with volumetric dilatometry. Polym Testing 2010;29(4):433-9.

[11] Shah DU, Schubel PJ. Evaluation of cure shrinkage measurement techniques for thermosetting resins. Polym Testing 2010;29(6): 629-39.

[12] Schoch KF, Panackal PA, Frank PP. Real-time measurement of resin shrinkage during cure. Thermochim Acta 2004;417(1):115-8.

[13] Parlevliet PP, Bersee HEN, Beukers A. Measurement of (post-)curing strain development with fibre Bragg gratings. Polym Testing 2010;29(3):291-301.

[14] Antonucci V, Giordano M, Cusano A, Nasser J, Nicolais L. Real time monitoring of cure and gelification of a thermoset matrix. Compos Sci Technol 2006;66(16):3273-80

[15] Karalekas D, Cugnoni J, Botsis J. Monitoring of process induced strains in a single fibre composite using FBG sensor: a methodological study. Compos A Appl Sci Manuf 2008;39(7):1118-27.

[16] Giordano M, Laudati A, Nasser J, Nicolais L, Cusano A, Cutolo A. Monitoring by a single fiber Bragg grating of the process induced chemo-physical transformations of a model thermoset. Sens Actuators, A 2004;113(2):166-73.

[17] Vacher S, Molimard J, Gagnaire H, Vautrin A. A fresnel's reflection optical fiber sensor for thermoset polymer cure monitoring. Polym Polym Compos 2003;12(4):269-76.

[18] Tai HJ, Chou HL. Chemical shrinkage and diffusion-controlled reaction of an epoxy molding compound. Eur Polym J 2000;36:2213-9.

[19] Lange J, Toll S, Månson J-AE, Hult A. Residual stress build-up in thermoset films cured above their ultimate glass transition temperature. Polymer 1995;36(16):3135-41.

[20] Yang DG, Jansen KMB, Ernst LJ, Zhang GQ, Bressers HJL, Janssen JHJ. Effect of filler concentration of rubbery shear and bulk modulus of molding compounds. Microelectron Reliab 2007;47(2-3):233-9.

[21] Hoa SV, Ouellette P, Ngo TD. Determination of shrinkage and modulus development of thermosetting resins. J Compos Mater 2009;43(7):783-803.
[22] Boyard N, Millischer A, Sobotka V, Bailleul JL, Delaunay D. Behaviour of a moulded composite part: modelling of dilatometric curve (constant pressure) or pressure (constant volume) with temperature and conversion degree gradients. Compos Sci Technol 2007;67(6):943-54.

[23] Boyard N, Vayer M, Sinturel C, Erre R, Delaunay D. Analysis and modeling of PVTX diagram of an unsaturated polyester resin, thermoplastic additive, and mineral fillers blend. J Appl Polym Sci 2003;88(5):1258-67.

[24] Nawab Y, Boyard N, Sobotka V, Jacquemin F, Casari P. Measurement and modelling of chemical shrinkage of thermoset composites. Key Eng Mater 2012;504:1129-34

[25] Nawab Y, Boyard N, Sobotka V, Casari P, Jacquemin F. A device to measure the shrinkage and heat transfers during the curing cycle of thermoset composites. Adv Mater Res 2011;326:19-28.

[26] Russell JD. Cure shrinkage of thermoset composites. SAMPE Quarterly 1992:28-33.

[27] Sadeghinia M, Jansen KMB, Ernst LJ. Characterization and modeling the thermo-mechanical cure-dependent properties of epoxy molding compound. Int J Adhes Adhes 2012;32:82-8.

[28] Holst M, Schänzlin K, Wenzel M, Xu J, Lellinger D, Alig I. Time-resolved method for the measurement of volume changes during polymerization. J Polym Sci, Part B: Polym Phys 2005;43(17):2314-25.

[29] Daniel IM, Karalekas D, Wang T-M, Gotro JT. Determination of chemical cure shrinkage in composite laminates. J Compos Technol Res Fall 1990;12(3):172-6.

[30] Olivier PA. A note upon the development of residual curing strains in carbon/ epoxy laminates. Study by thermomechanical analysis. Compos A Appl Sci Manuf 2006;37(4):602-16

[31] Boyard N, Vayer M, Sinturel C, Erre R, Delaunay D. Modeling PVTX diagrams: application to various blends based on unsaturated polyester-influence of thermoplastic additive, fillers, and reinforcements. J Appl Polym Sci 2004;92(5):2976-88.

[32] Millischer A. Transferts thermiques dans le procede d'injection BMC (Bulk Molding Compound). PhD thesis. Université de Nantes; 2000.

[33] Massé H, Arquis É, Delaunay D, Quilliet S, Le Bot PH. Heat transfer with mechanically driven thermal contact resistance at the polymer-mold interface in injection molding of polymers. Int J Heat Mass Transf 2004;47(89):2015-27.

[34] Pascault J-P, Williams RJJ, Sautereau H. Thermosetting Polymers. 4th ed. Marcel Decker Inc.; 2002.

[35] David S. Thermal conductivity of insulations using guarded hot plates, including recent developments and sources of reference materials. Meas Sci Technol 2001;12(12):R89.

[36] Bailleul JL, Delaunay D, Jarny Y. Determination of temperature variable properties of composite materials: methodology and experimental results. J Reinf Plast Compos 1996;15(5):479-96.

[37] Rabearison N, Jochum C, Grandidier JC. A FEM coupling model for properties prediction during the curing of an epoxy matrix. Comput Mater Sci 2009;45(3):715-24.

[38] Broyer E, Macosko CW. Heat transfer and curing in polymer reaction molding. AIChE J 1976;22(2):268-76.

[39] Podgaiz P, Riccardi CC, Williams RJJ. Cure of epoxy resins containing epoxidized polyols. Polym Eng Sci 1992;32(12):836-40.

[40] Prime RB. Differential scanning calorimetry of the epoxy cure reaction. Polym Eng Sci 1973;13(5):365-71.

[41] Kamal MR, Sourour S. Kinetics and thermal characterization of thermoset cure. Polym Eng Sci 1973;13(1):59-64.

[42] Adolf D, Martin JE. Calculation of stresses in crosslinking polymers. J Compos Mater 1996;30(1):13-34.

[43] Caruthers JM, Adolf DB, Chambers RS, Shrikhande P. A thermodynamically consistent, nonlinear viscoelastic approach for modeling glassy polymers. Polymer 2004;45(13):4577-97.

[44] Bailleul Jl. Optimisation du cycle du cuisson de pièces épaisses en matériau composite. Application a un préimprégné résine époxide/ fibres de verre. PhD thesis. Université de Nantes; 1997.

[45] Chern CS, Poehlein GW. A kinetic model for curing reactions of epoxides with amines. Polym Eng Sci 1987;27(11):788-95. 